Gerabah Dan Kajian Kawasan: Studi Kasus Kompleks Kebudayaan Buni Jawa Barat

\title{
Sumijati Atmosudiro
}

Keywords: pottery, ceramic, artifact, spatial, context

\section{How to Cite:}

Atmosudiro, S. Gerabah Dan Kajian Kawasan: Studi Kasus Kompleks Kebudayaan Buni Jawa Barat. Berkala Arkeologi, 15(3), 123-127. https://doi.org/10.30883/iba.v15i3.683

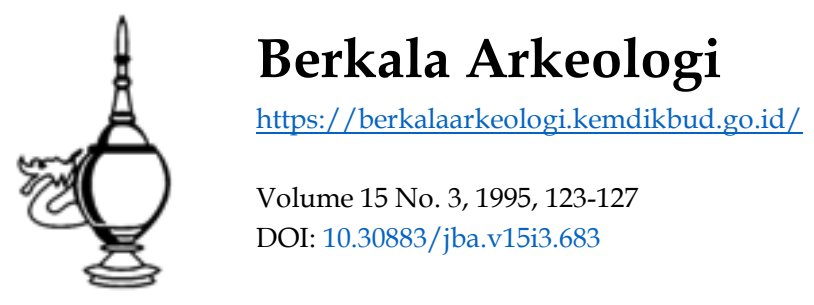

\section{(c) (1)(2)}

This work is licensed under a Creative Commons Attribution-NonCommercialShareAlike 4.0 International License. 


\title{
GERABAH DAN KAJIAN KAWASAN: STUDI KASUS KOMPLEKS KEBUDAYAAN BUNI JAWA BARAT
}

\author{
Sumijati Atmosudiro \\ (Jurusan Arkeologi FS-UGM)
}

I

Sejaian dengan perkembangan penelitian arkeologi Indonesia, maka arah penelitian yang pada mulanya hanya tertumpu pada kajian situs, perlu diperluas ke arah kajian yang regional atau berskala kawasan. Kajian berskala kawasan selain dapat merekonsruksi kehidupan masa lalu, juga dapat mengungkapkan terjadinya perubahan budaya. Dengan demikian hasil penelitian berskala kawasan dapat mengungkapkan dua paradigma arkeologi.

Perubahan kebudayaan dapat terjadi karena pengaruh dari dalam kebudayaan itu sendiri atau dari luar kebudayaan itu. Dalam proses perubahan kebudayaan, terutama perubahan yang terjadi akibat dari dalam, kawasan merupakan ruang adaptasi manusia. Berdasarkan asumsi itu, maka penelitian berskala kawasan dapat digunakan untuk melihat hubungan antara artefak dan lingkungan alam tempat artefak itu ditemukan (Butzer, 1984). Dengan demikian alam amat erat kaitannya dengan proses perubahan kebudayaan. Pernyataan itu senada dengan pendapat yang dikemukan oleh Binfodd (1983). Di samping itu, kawasan dapat pula dianggap sebagai tempat distribusi situs yang saling berinteraksi dan bertukar gagasan (Hedder \& Orton, 1967; Kusumohartono, 1994)

Orientasi kajian berskala kawasan menarik untuk diterapkan dalam penelitian yang menggunakan gerabah sebagai data primer. Gerabah sebagai hasil budaya materi memiliki fungsi penting dalam kehidupan manusia masa lampau, baik fungsi yang berhubungan dengan keperluan sehari-hari maupun fungsi yang ada hubungannya dengan kepercayaan. Data yang dapat membuktikan asumsi itu adalah adanya temuan gerabah di situs-situs yang berciri sebagai situs permu-kiman, penguburan, atau situs pemujaan.

Banyaknya temuan gerabah di beberapa situs, baik situs permukiman maupun situs kubur dapat memberi gambaran bahwa gerabah merupakan salah satu jenis barang atau benda yang amat diperlukan dalam kehidupan masa lampau, terutama pada masa prasejarah. Berdasarkan hal itu. maka manusia masa lampau berupaya mencari jalan agar kebutuhan akan gerabah dapat terpenuhi. Upaya memenuhi kebutuhan dengan dua cara, pertama adalah upaya menciptakan sendiri, bagi komunitas yang berdiam di wilayah yang menyediakan bahan, sedangkan cara kedua adalah melakukan hubungan antar komunitas, yakni bila daerahnya tidak memiliki bahan pembuatan gerabah. Jalinan komunikasi tersebut dapat berjalan, bila didukung oleh pemuki-man yang berpola.

Sehubungan dengan kondisi di atas, maka tidak tertutup kemungkinan bahwa gerabah dapat digunakan sebagai salah satu data dalam penelitian bersakala kawasan, misalnya untuk mengungkapkan pola permukiman atau aktivitas yang berhubungan dengan pertukaran. Untuk mencapai tujuan itu, langkah yang perlu diperhatikan di antaranya adalah analisis pada populasi sampel hendaknya dilakukan tidak hanya pada tingkat artefak atau tingkat subhimpunan. Analisis hendaknya sampai pada tingkat himpunan-himpunan artefak, agar hasilnya bila diperbandingkan dapat mengungkapkan persamaan dan perbedaan yang terjadi di tiap-tiap situs (Sumijati As, 1994).

Dasar pemikiran bahwa gerabah dapat digunakan sebagai data dalam penelitian berskala kawasan, di antaranya adalah persebaran gerabah yang luas baik di Indonesia maupun di luar Indonesia. Di Indonesia persebaran gerabah dimulai sejak masa prasejarah, yakni masa bercocok tanam dan masa perundagian. Persebaran gerabah prasejarah di Pulau Jawa menarik untuk diungkapkan, mengingat Pulau Jawa merupakan salah satu wilayah yang penting karena memiliki sisa-sisa aktivitas manusia masa lampau

Di Pulau Jawa, situs yang mengandung gerabah dalam jumlah banyak terdapat di Jawa Barat (Situs Anyer, Situs-situs Buni, dan Situs-situs di Kuningan), Jawa Tengah (Situs Plawangan dan Situs Gunung Wingko), serta Situs Kendeng Lembu di Jawa Timur (Heekeren, 1972; Sutayasa, 1973; Soejono, 1984). Di antara situs-situs tersebut, dalam tulisan ini hanya situs-situs yang termasuk dalam kompleks Buni yang akan dibahas. Pemilihan sampel tersebut didasari pertimbangan bah-wa antara situs-situs dalam kompleks tersebut dimungkinkan adanya hubungan fungsional, karena situs-situs tersebut berada dalam satu wilayah.

Sesuai dengan batasan wilayah pembahasan tersebut di atas, maka masalah yang ingin 
diketengahkan dalam tulisan ini adalah ada tidaknya komunikasi antar situs, bila ada komunikasi faktor-faktor apakah yang menyebabkannya? Komunikasi dapat menimbulkan masalah ada tidaknya perubahan budaya, dan apakah komunikasi satu-satunya faktor menyebab terjadinya perubahan kebudayaan?

Masalah-maslah tersebut di atas dapat diungkapkan bila di tiap-tiap kelompok dalam kompleks Buni memiliki budaya materi yang penciptaannya tidak didukung oleh kondisi lingkungannya. Di samping itu, komunikasi dalam kompleks Buni mungkin pula terjadi bila dalam kompleks Buni terdapat budaya materi yang tidak umum ditemukan di wilayah tersebut. Dengan demikian kondisi lingkungan merupakan salah satu faktor penyebab terjadinya komunikasi, yang pada gilirannya dapat menyebabkan terjadinya perubahan kebudayaan.

Upaya memecahkan masalah-masalah tersebut di atas, dilakukan dengan penajaman analisis Sutayasa dalam artikelnya tentang Kom-pleks Kebudayaan Buni di pantai utara Jawa Ba-rat, yang dimuat dalam majalah Manusia Indo-nesia, tahun 1973. Oleh karena terbatasnya data yang dimuat dalam artikel tersebut, serta sedi-kitnya artikel-artikel yang memuat dan memba-has tentang kompleks Buni, maka dalam ana-lisis mengalami kendala-kendala. Di antara ken-dala itu adalah ketepatan lokasi tiap-tiap situs serta rincian jenis-jenis temuan baik yang berupa artefak maupun nonartefaknya. Dengan demikian pemecahan masalah di atas hanya secara garis besar sesuai dengan data yang ada.

\section{II}

Pada dasarnya kompieks Buni terdiri atas tiga wilayah yang ada di sepanjang pantai utara Jawa Barat, di daerah aliran sungai yakni Sungai Cisedane, Ciliwung, Bekasi, Citarum, dan Ciparaga. Berdasarkan ciri-ciri gerabahnya, maka gerabah di kompleks tersebut dapat dibedakan menjadi dua fase yaitu fase pertama atau fase bercocok tanam dan fase kedua atau fase perundagian. Ditinjau dari persebarannya Situs-situs Buni dapat dikelompokkan menjadi tiga, yaitu kelompok Tanggerang, kelompok Bekasi, dan kelompok Rengasdengngklok. Dari ketiga kelom-pok tersebut kelompok Tanggerang memiliki si-tussitus yang paling jauh dari garis pantai, di antaranya ada yang berjarak $50 \mathrm{~km}$.

Tiap-tiap kelompok tersebut terdiri atas beberapa situs, misalnya kelompok Tanggerang terdiri atas Situs Serpong, Curug, dan Mauk, sedangkan kelompok Bekasi terdiri atas Buni, Ke- rangkeng, Puloglatik, Pulo Rengas, Kedungri-ngin Bulkatemu, Rawa Menembe, Batujaya, dan Tugu Kelompok Rengasdengklok terdiri atas Ba-bakan Pedes, Tegalkunir, Kampung Krajan, Pu-loklapa, Cibutek, Kebakkendel, Karangjati, dan Cilogo (Sutayasa, 1973)

Gerabah yang ditemukan di kompleks Bu-ni, baik di Tanggerang, Bekasi maupun Rengasdengklok menunjukkan persamaan dalam aspek teknologi. Persamaan itu meliputi teknik pembentukan, yakni digunakannya teknik tatap-pelandas yang dipadukan dengan tangan. Di antara tatap yang digunakan terdapat tatap berukir, yang bila digunakan dapat menghasilkan pola hias anyaman dan duri ikan. Kedua poia hias tersebut tampak amat populer di daerah pantai utara Jawa Barat, terutama di daerah aliran Sungai Cisedane atau pada kerlompok Tanggerang. Gerabah yang mempunyai pola hias anyaman dan duri ikan merupakan gerabah fase pertama, sehingga jenisnya terbatas dan bentuknyapun sederhana.

Jenis gerabah fase pertama hanya terdiri atas periuk dan cawan. Jenis periuk dapat dibedakan menjadi dua yaitu periuk dengan bentuk badan membulat dan periuk dengan karinasi. Periuk dengan badan mermbulat ditemukan di ketiga kelompok, sedangkan periuk berkarinasi lebih banyak ditemukan di kelompok Bekasi dan Rengasdengklok. Jenis cawan dapat pula dibedakan menjadi cawan beralas cembung dan cawan beralas rata. Cawan beralas cembung ditemukan diketiga kelompok, sedangkan cawan beralas rata lebih banyak ditemukan di kelompok Bekasi dan Rengasdengklok (Sutayasa, 1975).

Di antara ketiga kelompok tersebut di atas, gerabah kelompok Bekasi dan Rengasdengklok lebih banyak menunjukkan persamaan bila dibandingkan dengan kelompok Tanggerang. Perbedaan anatara kelompok Bekasi Rengasdengklok selain mencakup jumlah temuan jenis periuk dan cawan beralas rata, perbedaan tampak pula pada warna gerabah serta prosentase unsur dalam bahan bakunya. Warna gerabah kelompok Tanggerang adalah coklat kekuningan, sedangkan gerabah kelompok Bekasi - Rengasdengklok adalah kelabu. Kondisi gerabah kelabu lebih baik bila dibandingkan dengan gerabah yang berwarna coklat kekuningan, sehingga kondisi gerabah kelompok Tanggerang lebih rapuh bila dibandingkan dengan gerabah Bekasi-Rengasdengklok.

Dalam fase kedua kedudukan gerabah di kompleks Buni tampak tidak mengalami pergeseran, walaupun telah dikenal benda-benda dari bahan logam. Bahkan dalam kelompok Bekasi-Rengasdengklok gerabah fase pertama mengalami perkembangan baik dalam aspek teknologi maupun fungsi. Dalam aspek tekhnologi tampak digu- 
nakanya tekhnik roda putar yang dipadukan dengan tatap pelandas. Penggunaan tatap berukir tetap dilanjutkan, namun tekhnik hias tidak hanya dengan tekhnik tekan, melainkan juga digunakan teknik gores. Akibat bertambahnya teknik pengetrapan pola hias tersebut, menyebabkan gerabah di kompleks Bekasi-Rengasdengklok memiliki pola-pola hias yang lebih banyak variasinya. Tambahan variasi pola hias itu adalah munculnya pola hias geometris, di antaranya adalah segitiga (tumpal) dan lingakaran memusat. Di antara pola hias lingkaran memusat tersebut ada pola hias lingkaran memusat yang dikelilingi garis-garis pendek serta lingkaran memusat dengan pola hias berbentuk persegi di tengahnya. Pola hias lingkaran memusat menjadi ciri pola hias gera-bah kompl eks Buni (Soejono, 1984)

Perkembangan lain yang tampak dalam kelompok Bekasi Rengasdengklok adalah bertambahnya jenis dan bentuk gerabah. jenis gerabah tidak hanya terdiri atas periuk dan cawan, melainkan juga dikenal jenis kendi, tempayan, dan tutup.

Baik periuk maupun cawan terdiri atas berbagai ukuran, di antaranya ada yang berukuran mini serta cawan yang berkaki. Cawan berka-ki di antaranya ada yang memiliki lubang berjum-lah dua atau tiga yang ditempatkan pada bagian bibir. Berbeda dengan kondisi kedua kelompok tersebut, gerabah Tanggerang tampak tidak mengalami perubahan dalam aspek tekhnologi, meskipun benda-benda logam telah dikenal.

Munculnya gerabah berukuran kecil atau mini dan cawan-cawan berkaki yang bentuknya menyerupai pedupaan, dapat memberi gambaran bahwa dalam kompleks Buni fungsi gerabah tidak hanya digunakan untuk memenuhi kebu-tuhan sehari-hari, melainkan juga digunakan se-bagai peralatan upacara. Data lain yang mem-perkuat hal itu adalah temuan gerabah berukuran mini dan cawan berkaki di situs kubur Cigugur Jawa Barat (Teguh Asmar, 1982).

Di kompleks Buni selain ditemukan gerabah jenis wadah dan nonwadah, ditemukan pula bandul-bandul jaring dengan berbagai variasi di antaranya berbentuk bulat, lonjong, setengah bulatan, dan kerucut. Bandul-bandul jaring tersebut mempunyai lubang sebagai ikatan talinya. Di antara bandul-bandul jaring itu ada yang mempunyai pola hias jalla dan duri ikan. Temuan bandul jaring itu dapat memberi gambaran bahwa kehidupan pantai yang akrab dengan laut telah berlangsung di daerah ini.

Selain jenis-jenis temuan di atas dalam kelompok Rengasdengklok yakni di Cibutek dan Kobak-kendel (Walker \& Santoso,1977) terdapat gerabah kelabu yang menunjukkan perbedaan dengan yang berasal dari kelompok Bekasi. Ditinjau dari teknik pembentukannya gerabah tersebut dibuat dengan tatap-pelandas yang dipadukan dengan roda putar. Ciri lain dari gerabah itu adalah adanya pola hias lingkaran yang ditempatkan di bagian dalam dari dasar sebuah baki. Berdasarkan pola hias itu gerabah yang ditemukan di Aritmedu (India Selatan). Sementara ini, gerabah yang sama ditemukan di Sembiran Bali (Ardika and Bellwood, 1991).

Gerabah fase kedua menurut beberapa ahli mempunyai persamaan. dengan tradisi gerabah Bau Malaya, yang berkembang di Serawak dan Malaysia. Persamaan tersebut tampak pada teknik pembentukanya, terutama digunakanya tatap berukir.Tatap berukir tersebut apabila ditekankan pada permukaan gerabah saat masih basah, dapat menimbulkan pola-pola hias di antaranya adalah pola hias geometris. Selain menunjukkan persamaan dengan tradisi Bau-Malaya, gerabah Buni juga memiliki persamaan dengan gerabah Sa-huynh-Kalanay, meskipun kurang menonjol bila dibandingkan dengan Bau-Malaya. Persamaan dengan Sa-hunyh-Kalanay dtunjukkan dengan adanya bentuk-bentuk cawan yang berkarinasi

Selain gerabah, di kompleks Buni ditemukan pula beliung persegi yang terupam halus. Keberadaan beliung tersebut disejajrkan dengan gerabah fase pertama. Temuan beliung persegi yang paling banyak adalah di kelompok Tanggerang, dengan berbagai variasi yakni beliung persegi, belincung, dan beliung berukuran kecil yang berfungsi sebagai pahat. Beliung-beliung tersebut dibuat dari jenis batuan gamping, agat, jasper, dan batu kali. Pada beberapa beliung menunjuk-kan adanya perimping bekas pemakaian yang intensif. Selain beliung berimping terdapat pula yang tidak menunjukkan adanya bekas-bekas pemakaian, sehingga memungkinkan bahwa beliung tersebut tidak digunakan untuk memenuhi kebutuhan sehari-hari. Tidak adanya perimping dan pengerjaannya yang halus, dapat menimbulkan asumsi bahwa beliung tersebut digunakan untuk upacara-upacara tertentu (Sutayasa, 1975).

Berdasarkan bentuknya, beliung Kompleks Buni dapat dibedakan menjadi tiga tipe, yakni ti-pe 1,2 , dan 3 . Tipe 1 , merupakan beliung yang ter-tua dan ditemukan tersebar di ketiga kelompok. Secara garis besar beliung tipe 1 mempunyai ukuran lebar bagian pangkal sama dengan ukuran bagian tajaman, sedangkan tipe 2 memiliki ukuran bagian pangkal lebih kecil bila dibandingkan dengan bagian pangkal. Tipe ini dianggap lebih muda dari tipe 1. Tipe 3 diperkirakan yang paling muda, karena mempunyai bentuk menyerupai kapak perunggu. Selain beliung persegi, kompleks Buni juga mengandung temuan asesori 
berupa gelang dan manik-manik yang dibuat dari batu. Gelang dibuat dari batu jasper dan kalsedon, sedang manik-manik dari batu kornelian. Di samping dari batu, manik-manik juga ada yang dibuat dari gigi binatang.

Dalam kompleks Buni, selain temuan yang berupa budaya materi, terdapat pula sisa-sisa makanan yang terdiri atas cangkang kerang, tulang kepiting, tulang-tulang ikan baik ikan darat maupun ikan laut, dan tulang babi. Di samping itu, ditemukan pula tanda-tanda penguburan misalnya di Kobakkendel, Babakan Pendes, Kampung Krajan, dan Buni. Menurut Soejono penguburan di tempat-tempat tersebut adalah penguburan dengan posisi tertelentang tanpa peng-gunakan wadah.

Di luar temuan yang dibuat dari batu, di kompleks Buni memiliki pula budaya materi yang dibuat dari perunggu berupa kapak. Berdasarkan bentuk tangkainya, bentuk pinggangnya, dan bentuk tajamannya, kapak perunggu kompleks Buni dibedakan menjadi tiga tipe, yakni tipe 1,2, dan 3 (Sutayasa, 1975). Tipe 1 mempunyai tajaman cembung, tangkainya melengkung atau rata, berukuran kecil. Tampaknya kapak ini digu-nakan untuk memenuhi keperluan sehari-hari. Tipe 2 adalah kapak yang tempat pegangan tangkainya berbentuk ekor burung sriti. Berdasarkan bentuknya maka kapak ini digunakan untuk keperluan upacara. Tipe ini ditemukan tersebar di ketiga kelompok, namun yang paling banyak adalah di kelompok Tanggerang. Bentuk yang sama banyak ditemukan di situs pemujaan di Pasir Angin Bogor. Tipe 3 adalah kapak yang mempunyai pegangan yang agak lebar, dengan bentuk tajaman melebar sehingga menyerupai kipas, bagian pinggang ramping. Berdasarkan bentuknya yang tidak praktis, maka kapak tipe ini juga digunakan untuk upacara.

Di antara ketiga tipe kapak tersebut, kapak ipe 1 merupakan hasil produksi lokal di wilayah Bekasi, karena di Batujaya ditemukan cetakan kapak perunggu yang sama dengan kapak tipe 1. Temuan cetakan tersebut sekaligus dapat memberi bukti bahwa di Pulau Jawa terdapat lokasi pembuatan benda-benda perunggu, sebagai upaya memenuhi kebutuhannya.

III

Berdasarkan persebaran situs-situs kompleks Buni dapat diperoleh gambaran bahwa kelompok Tanggerang berada di aliran Sungai Cisedane. sedangkan kelompok Bekasi di muara dan di aliran Sungai Bekasi dan Ciliwung, dan aliran Sungai Citarum untuk kelompok Rengasdengklok. Keberadaan situs-situs di aliran atau di muara sungai seperti Situs-situs Buni merupakan bukti bahwa manusia cenderung memilih kawasan pemusatan populasi di daerah-daerah yang dekat dengan sumber air. Pemusatan populasi di tepi pantai dan di tepi sungai mempunyai tujuan agar aktivitas pencarian makanan yang berupa ikan atau kerang, dapat terpenuhi dengan mu-dah. Di sisi lain, pemusatan populasi di tepi su-ngai dapat memperlancar perjalanan, karena perjalanan melalui hutan belukar dapat dihindari (Krober, 1953)

Pemusatan populasi pada gilirannya dapat membentuk suatu pemukiman yang merupakan tempat tinggal bersama, dengan tujuan tertentu dan adanya perasaan satu wilayah. Kondisi yang sama tampak terjadi di panta utara Jawa Barat, yang memiliki situs-situs di aliran sungai dan di tepi pantai. Dengan demikian pertumbuhan situssitus di daerah ini menunjukkan pola berjajar, sesuai dengan bentang lahan yang berupa aliran sungai dan garis pantai. Pola berjajar di sepanjang pantai tampak pada kelompok Bekasi, sedangkan pola berjajar menurut aliran sungai tampak pada kelompok Tanggerang dan Rengasdengklok. Munculnya situs-situs pemukiman di tiap-tiap kelompok sesuai dengan bentang lahannya dapat berakibat terjadinya suatu pola permukiman di wilayah tersebut.

Sesuai dengan jenis temuannya, komuni-tas kompleks Buni dapat digolongkan dalam masyarakat bercocok tanam yang hidup dari pertanian dan menangkap ikan. Dalam masyarakat bercocok tanam dikenal adanya prinsip timbal balik yang merupakan sistem tukar menukar kuajiban dan barang atau benda. Sistem itu merupakan daya pengikat dan penggerak dalam kehidupan bercocok tanam (Koetjaraningrat).

Kebutuhan hidup manusia semakin bertambah, sesuai dengan perkembangan hidupnya yang semakin kompleks. Akibat dari kondisi itu adalah keterbatasan dalam memenuhi kebutuhan hidupnya sehingga terjadi saling ketergantungan. Pada awalnya, pemenuhan kebutuhan itu dilakukan dengan pertukaran yang tidak memperhitungkan untung dan rugi (reprocity). Dari pertukaran reprocity berkembang menjadi pertukaran dengan sistem distribusi. Sistem inilah yang tampaknya yamg dilakukan oleh komunitas di pantai utara Jawa Barat

Asumsi tersebut dicoba diungkap dari kondisi yang terjadi di tiga kelompok dalam kom-pleks Buni. Dalam kelompok Bekasi-Rengas-dengklok berdasarkan temuan gerabahnya dapat diketahui adanya perkembangan dalam tekno-logi, sehingga dapat memunculkan jenis, bentuk, dan pola hias yang lebih banyak variasinya diban-dingkan dengan kelompok Tanggerang. Adanya 
perkembangan itu menyebabkan munculnya asumsi bahwa gerabah Buni memiliki unsur BauMalaya. Selain itu, di kelompok Rengasdengklok terdapat jenis gerabah jenis kelabu yang berbeda dengan gerabah kelabu, kompleks Bekasi dan Rengasdengklok sendiri. Di sisi lain, tekhnologi gerabah di kelompok Tanggerang tidak berkembang namun justru di kelompok itu muncul kemahiran membuat kapak perunggu. Kondisi tersebut menyebabkan kebutuhan kapak perunggu dalam kelompok Bekasi-Rengasdengkiok terpenuhi dari kelompok Tanggerang.

Berdasarkan variasi temuan kapak perunggu dan jenis artefak lain, dapat dikemuka-kan bahwa pertukaran kebutuhan tidak hanya dilakukan dalam kelompok kompleks Buni, melainkan juga dengan daerah di luar Buni. Kapakkapak perunggu yang didatangkan dari luar adalah kapak perunggu tipe 2 dan 3, yakni kapak yang berfungsi untuk upacara. Sedangkan pertukaran beliung persegi dan assesori dilakukan dengan situs-situs bengkel di daerah pedalaman, misalnya Karangnunggal (Tasikmalaya).

Pertukaran beliung persegi di pantai utara Jawa Barat tampak ramai. Hal itu terbukti dengan persebaran beliung persegi di ke-tiga kelompok, meskipun yang paling menonjol adalah di kelompok Tanggerang. Menonjolnya beliung persegi di kelompok Tanggerang kurang didukung oleh kualitas gerabahnya, dengan demikian ada kemungkinan di kelompok Tanggerang memiliki barang yang dibutuhkan oleh kelompok produsen beliung persegi dan assesori

Produsen beliung persegi dan assesori di daerah pedalaman tentunya membutuhkan gerabah sebagai salah satu keperluan hidupnya. Untuk memenuhi keperluan itu komunitas produsen perlu mengadakan hubungan dengan komunitas lain, di antaranya adalah komunitas kompleks Buni (kelompok Bekasi-Rengasdengklok). Kebenaran asumsi itu perlu didukung dengan penelitian di situs-situs bengkel di daerah pedalaman untuk mengumpulkan temuan gerabah. Hasil pengumpulan itu dianalisis baik tekhnologi (meliputi bahan, warna, tekhnik pembentukan, pola hias) maupun jenis/gaya. Hasil analisis yang menunjukkan persamaan dengan kelompok BekasiRengasdengklok dapat membuktikan bahwa antara kedua komutis tersebut telah menjalin komunikasi.

Berdasarkan uraian di atas dapat dikemukakan bahwa dalam kompleks Buni , terutama masabercocok tanam sampai masa perundagian terjadi suatu perubahan kebudayaan. Perubahan tersebut tampak dalam teknologi pembuatan gerabah dan munculnya kemahiran membuat benda-benda logam perunggu.

\section{KEPUSTAKAAN}

Ardika,I Wayan and Bellwood Peter. 1991., Sembiran: The Begining of Indian Contact with Bali. Anitiquity. 65:221-232

Buzer,Karl,W.,1984. Archeologyas Human Ecology Cambridge Unversity Press Cambridge

Heekeren,H.R.van.1972. The Stone of Indonesia VKI.21 Martinus Nyhoffs Gravenhage

Hodder, lan and Clive,Orton.1976., Spatial AnaIysis in Archaeology. London Cambridge University Press.

Kusumohartono, Bugie, M.H. 1994., Proses Perubahan Kebudayaan dan Kajian Kawasan Dalam Arkeologi. EHPA 1994. Pusat Penelitian Arkeologi Nasional.

Pryor,L.Frederic., 1968. The Origin of Economy Academic Press. New York.

Soejono,R.P.(ed).1984. Sejarah Nasional Indonesia I. Balai Pustaka, Jakarta

Sumijati Atmosudiro.1994 Gerabah Prasejarah Di Liang Bua, Melolo, dan Lewoleba: Tinjauan Teknology dan Fungsinya. Disertasi. Universitas Gadjah Mada, Yogyakarta.

Sutayasa, I Made.1973. The Study of Prehistoric Pottery in Indonesia. Nusantara.4.2.6782

1975. Sebuah Tinjauan Tentang Kompleks Kebudayaan Buni di Pantai Jawa Barat. Manusia Indonesia. 83-103

Teguh Asmar. 1982. Kubur Peti Batu Kuningan, Jawa Barat., PIA:69-74. Pusat Penelitian Arkeologi Nasional. Jakarta.

Walber, M. J. S. and Santosa S. 1977. RamanoIndian Roulatted Pottery in Indonesia. Mankind 11: 39-45 